\title{
MEMORIA Y NOVELA GRÁFICA: LA YUXTAPOSICIÓN DE LO COTIDIANO Y DE LA GUERRA EN LA OBRA DE ZEINA ABIRACHED
}

\author{
Eva Pich-Ponce \\ Universidad de Sevilla \\ epich@us.es
}

\begin{abstract}
RESUMEN: A través del análisis de la novela gráfica Mourir, partir, revenir: Le jeu des hirondelles, creada por la autora libanesa Zeina Abirached, este estudio pretende mostrar el interés que tiene la novela gráfica para la transmisión de relatos traumáticos. Destacaremos cómo Abirached utiliza y combina la imagen y el texto de forma hábil para relatar los acontecimientos vividos durante la guerra del Líbano de 1984. Observaremos sobre todo cómo yuxtapone el microcosmos de solidaridad en el que viven los personajes y las imágenes de un mundo exterior violento y hostil marcado por la guerra. Mediante esta novela gráfica, Abirached no sólo intenta plasmar sus propios recuerdos, sino que realiza todo un trabajo de recuperación de la memoria histórica de su país.
\end{abstract}

PALABRAS CLAVE: rutina, memoria, novela gráfica, Libano, Abirached, guerra.

\section{MÉMOIRE ET ROMAN GRAPHIQUE: LA JUXTAPOSITION DU QUOTIDIEN ET DE LA GUERRE DANS L'OEUVRE DE ZEINA ABIRACHED}

\begin{abstract}
RÉSUMÉ: À travers l'analyse du roman graphique Mourir, partir, revenir: Le jeu des hirondelles, créé par l'auteure libanaise Zeina Abirached, cette étude vise à montrer l'intérêt que le roman graphique peut avoir pour la transmission des récits traumatiques. Nous soulignerons comment Abirached combine l'image et le texte d'une manière habile pour raconter les événements vécus pendant la guerre du Liban de 1984. Nous observerons surtout comment elle juxtapose le microcosme de solidarité dans lequel habitent les personnages et les images d'un monde extérieur violent et hostile, marqué par la guerre. À travers ce roman graphique, Abirached n'essaye pas seulement de présenter ses propres souvenirs, mais aussi de réaliser tout un travail de récupération de la mémoire historique de son pays.

MOTS CLÉS: routine, mémoire, roman graphique, Liban, Abirached, guerre.
\end{abstract}




\section{Memoria, imagen y novela gráfica}

Como ha señalado Santiago García, se entiende por novela gráfica "un tipo de cómic adulto moderno que reclama lecturas y actitudes distintas del cómic de consumo tradicional" (2010: 16). La novela gráfica presenta una temática y unas estructuras complejas, que incluyen frecuentemente la inserción de elementos autobiográficos. En Persépolis (2000), Marjane Satrapi presenta su infancia en el Irán de la revolución islámica. Miriam Katin en We are on our own (2006) muestra cómo su madre y ella consiguieron escapar durante la invasión nazi de Budapest de 1944. La sudafricana Karlien de Villiers en Meine Mutter war Eine Schöne Frau (2006) presenta la historia de su infancia en el contexto del apartheid. Las obras de Zeina Abirached se inscriben dentro de esta corriente de autoras contemporáneas para las cuales el papel del recuerdo es esencial. Según Catalina Montenegro González, las novelas gráficas de estas escritoras, "permiten la reconstrucción de las subjetividades de la infancia como recuperación de la memoria" (2011: 19).

Zeina Abirached es una historietista libanesa que reside actualmente en Francia. Nació en Beirut en 1981, en plena guerra civil. Tras graduarse en la Academia Libanesa de Bellas Artes, se especializó en animación en l'École Nationale des Arts Décoratifs de París. Su obra Beyrouth-Catharsis obtuvo el Primer Premio del Festival de Cómic de Beirut en el 2002, y fue publicada en Francia en el 2006, así como 38, rue Youssef Semaani. Un año después, Abirached publicó Mourir, partir, revenir: Le jeu des hirondelles (2007), una novela gráfica en la que la autora rememora su niñez en el Líbano de los años 80. Dicha obra fue traducida al español por Lucía Bermúdez Carballo bajo el título de El juego de las golondrinas (Madrid, Sins Entido, 2008).

El género de la novela gráfica permite plasmar la experiencia autobiográfica y la memoria a través de combinaciones visuales y verbales (Chaney 2011: 6). Las imágenes visuales tienen una fuerza innegable puesto que no sólo representan escenas y experiencias del pasado, sino que son capaces de transmitir una experiencia emocional o corporal (Jill Bennett 2005: 36). El propio trauma ha sido frecuentemente definido como la reiteración incesante de una serie de imágenes: según Cathy Caruth, estar traumatizado consiste precisamente en estar poseído por una imagen o por un acontecimiento que se repite en la mente del sujeto, al no haber sido asimilado en el momento del suceso (Caruth 1995: 4-5). Más allá del carácter violento del acontecimiento, es el hecho de que el sujeto no haya podido asimilarlo lo que constituye el trauma. El relato de los hechos traumáticos es fundamental para que el sujeto se libere de esas imágenes que parecen poseerlo. 
Elisabeth El Refaie ha mostrado cómo la autobiografía se ha visto enriquecida por las posibilidades formales que ofrecen los cómics, ya sea mediante el juego entre las palabras y las imágenes o entre la secuencia y su disposición en la página (E1 Refaie 2012: 4). La forma del cómic es particularmente interesante para transmitir la experiencia subjetiva del tiempo y la forma en la que funciona la memoria:

[...] the medium seems to be particularly well suited to the task of conveying the human experience of time, since many of its formal features follow patterns that reflect the way memory itself works. Examples include the gaps - both between verbal and visual meaning, and between individual panels - that characterize comics, as well as the fact that in this medium meanings often emerge through associative links across a page or even a whole work (El Refaie 2012: 95)

Según El Refaie, las cualidades formales y materiales del cómic hacen que éste sea particularmente atractivo para contar las experiencias vividas y particularmente aquellas que implican acontecimientos dolorosos o traumáticos, puesto que éstos se recuerdan generalmente en forma de impresiones asociativas o de fragmentos (El Refaie 2012: 133). Johnny Youssef Francis también sostiene que la utilización de la novela gráfica para relatar acontecimientos traumáticos vividos en el pasado permite expresarlos de forma visual mediante el uso del espacio, el color, el texto escrito, y la posición de los encuadres en cada página. Como señala: "All of these stylistic choices beyond just the words and images themselves make the graphic novel a highly complex outlet for the expression of traumatic events" (Francis 2017: 1). Asimismo, Hillary Chute, en Graphic Women (2010), destaca que en el caso de relatos que evocan una memoria traumática, la imagen revela frecuentemente aspectos de esa memoria de los que el artista no es consciente o que no es capaz de verbalizar (2010: 3). Carla Calargé y Alexandra Gueydan-Turek también han señalado la especificidad visual y estética de este género, en el que la imagen adquiere un lugar privilegiado, sustituyendo a lo verbal cuando las palabras son difíciles de encontrar (2014: 207).

Zeina Abirached utiliza la novela gráfica para contar sus recuerdos, su experiencia durante la guerra del Líbano de 1984. El uso testimonial de la novela gráfica cuenta ya con una larga trayectoria de autores, y comenzó con la publicación de la obra Maus de Art Spiegelman, en los años 80, una obra en la que el autor relataba el horror vivido por su padre en un campo de concentración nazi. Se puede realizar una distinción entre la novela gráfica autobiográfica, que retoma vivencias personales o de familiares, y el cómic-reportaje utilizado por algunos 
autores para dar testimonio de las tragedias del mundo: Palestina (1992) de Joe Sacco, Baghdad Journal (2005) de Steve Mumford, My Dorchester Neighbors (2006) de Greg Cook, War Fix (2006) de David Axe, etc. Hillary Chute ha mostrado cómo los cómics se han convertido en un género esencial dentro de las formas documentales:

The form of comics has taken center stage among a range of documentary forms - moving forward, say, from the era of New Journalism and cinema vérité - that innovate the parameters of documentary, investigating historical trauma and even the concept of history itself (Chute 2016: 6-7)

Sin embargo, como afirman Carla Calargé y Alexandra Gueydan-Turek, hasta hace poco, el cómic y la novela gráfica estaban prácticamente ausentes de la tradición literaria y artística libanesa (2014: 207).

Tanto la novela gráfica autobiográfica como el cómic-reportaje son efectivos por el poder de impacto que tienen las imágenes, pero también por el punto de vista subjetivo que se adopta, puesto que permiten al creador aparecer como personaje, facilitando de esta manera la transmisión no sólo de la acción y de la información, sino también de las emociones. De esta manera, como ha mostrado Christophe Dabitch (2009), se reivindica un punto de vista humano y un sentido crítico. Jan Baetens (2013: 68) ha destacado la importancia que adquiere la presencia narrativa en la novela gráfica: "The story is no longer seemingly telling itself: it is presented and filtered through a narrative voice or tone, which can be made directly visible in the work".

Según Carolane Verreault-Côté, la dimensión gráfica de un relato permite reforzar el lazo entre el compromiso del autor y el proceso narrativo de la autorepresentación. La presencia del autor como personaje legitima la dimensión comprometida de la obra al afianzarse en lo vivido (Verreault-Côté 2012: II). En la novela gráfica Mourir, partir, revenir: Le jeu des hirondelles, Zeina Abirached pone de relieve cómo era la vida durante la guerra civil libanesa, que enfrentó a las facciones cristianas y musulmanas del país. La autora muestra la amenaza constante de los misiles, los cambios sufridos por la ciudad a causa de la guerra y, sobre todo, la rutina y la solidaridad de los habitantes en pleno conflicto bélico. En la contraportada de la obra, Abirached explica que decidió crear esta novela gráfica tras ver un reportaje sobre el Beirut de 1984. En él, los periodistas entrevistaban a varias personas que vivían en una calle situada en la línea de demarcación. Una de las personas entrevistadas era la abuela de la escritora. Al 
ver este reportaje, Abirached decidió crear una obra sobre su niñez pasada en Beirut durante la guerra, para dar testimonio de lo sucedido. En una entrevista, Abirached describe la importancia que tiene para ella la relación texto-imagen en su construcción del recuerdo:

J'ai ressenti un jour l'urgence de raconter un souvenir très précis. Je me suis mise à écrire. Très vite, j'ai éprouvé le besoin de dessiner pour construire l'histoire avec des images et des mots, construire l'histoire dans ce rapport du texte à l'image. Je me suis mise à faire de la bande dessinée comme ça, sans préméditation, et ça a donné [Beyrouth] Catharsis, un travail de mémoire, urgent pour moi [...] (Abirached y Bouillon 2015: 140)

Hirsch (2001) ha destacado la importancia de las imágenes, de las fotografías, y su impacto tanto en los supervivientes como en los descendientes de éstos. En su estudio, Hirsch se centra principalmente en aquellas generaciones que no han vivido directamente los acontecimientos traumáticos, pero que han estado marcadas por la experiencia de sus padres. Según ella, esta segunda generación, a la que llama postmemorial generation, realiza un trabajo de formulación y de reconstrucción de los hechos:

[...] the postmemorial generation, in displacing and recontextualizing these wellknown images in their artistic work, has been able to make repetition not an instrument of fixity or paralysis or simple retraumatization, as it often is for survivors of trauma, but a mostly helpful vehicle of working through a traumatic past (Hirsch 2001: 218)

Aunque Abirached sí que presenció los acontecimientos, era tan sólo una niña, con una visión por lo tanto limitada de lo que estaba sucediendo. En este sentido, su experiencia se asemeja a la de la segunda generación descrita por Hirsch.

Se ha escrito mucho sobre la importancia de la fotografía como huella o rastro del pasado, como una señal inequívoca del haber estado en ese lugar. Barthes ya señaló la importancia de la fotografía como fuerza evidencial (1980) y Barbie Zelizer destaca que la fotografía materializa la memoria (1998). Según Hirsch:

Photographs in their enduring 'umbilical' connection to life are precisely the medium connecting first - and second - generation remembrance, memory and postmemory. They are the leftovers, the fragmentary sources and building blocks, shot though with holes, of the work of postmemory. They affirm the past's existence and, in their flat two-dimensionality, they signal its unbridgeable distance (Hirsch 2011: 23) 
Es interesante observar que es un elemento visual, el reportaje, lo que impulsa a Abirached a intentar reconstruir su pasado. Para esta reconstrucción, utiliza un medio igualmente visual: la novela gráfica. En este sentido, podríamos considerar que el lector de dicha obra se convierte él mismo en un postmemorial viewer. Como señala Hirsch (2001: 225): "postmemorial viewers do more than listen to the witness; they gaze at the image with her and thus they can reenact, recall in the very sensations of the body".

Como afirma Rockford, sólo el paso del tiempo permite organizar los recuerdos en un contexto histórico: "Chez Abirached, les œuvres représentent ce travail de mémoire qui lui permet d'analyser les souvenirs qui sont cicatrisés dans sa mémoire. Elle utilise l'écriture et les illustrations comme un exercice d'organisation qui lui permet de digérer ses expériences vécues" (2015: 52). Abirached explica cómo tras la guerra civil, no se realizó ningún esfuerzo por preservar el recuerdo de lo que había sucedido:

Il y a un énorme non-dit. [...] La ville est donc pleine de cette mémoire et pour autant, pas une seule plaque n'indique qu'ici il y a eu tant de morts. Il n'y a pas eu du tout de travail de mémoire par rapport à la ville et à ces questions de territoire. Le Beyrouth de mon enfance était en train de disparaître, tout comme les traces de ce que nous avions vécu. Il me semblait donc important de dire voilà, ça s'est passé (Abirached y Bouillon 2015: 140)

Según Ricœur, el testimonio constituye la estructura fundamental de transición entre la memoria y la historia (2000: 26). Sin embargo, el acontecimiento traumático se sitúa fuera del lenguaje, fuera de los parámetros de causalidad, de secuencialidad. Los supervivientes de un trauma no viven con recuerdos de un pasado sino con unas imágenes que se repiten, un acontecimiento sin conclusión (Felman y Laub 1992: 69). Abirached, de hecho, señala en Je me souviens (2008) que no se acuerda del último día de la guerra. Como señala Rockford, esta laguna en la memoria de la autora justifica el carácter inacabado de su trabajo y representa la ausencia de un verdadero final de la guerra, puesto que ésta seguirá marcando los pensamientos y la vida de los libaneses (2015: 50-51).

La historia de Mourir, partir, revenir: Le jeu des hirondelles está narrada en primera persona. Más que en el conflicto bélico, la novela gráfica de Zeina Abirached se centra en el microcosmos de un edificio y en la historia de cada personaje que allí habita. De esta manera, y a través de la mirada inocente de la narradora, una niña, la autora realza el impacto de la guerra en la vida cotidiana de 
la población. Los recuerdos más banales de su vida doméstica se mezclan con los de la violencia del conflicto bélico. Abirached reconstruye el pasado. Reconstruye sus recuerdos y los recuerdos de este espacio en busca de una memoria colectiva.

\section{Un contexto espacial marcado por la guerra}

La acción de Mourir, partir, revenir: Le jeu des hirondelles es mínima: Sami y Nour, los padres de la narradora se quedan aislados, por culpa de los bombardeos, en casa de la abuela, a unas manzanas de donde viven. Los niños les esperan en casa, acompañados por los vecinos, que van entrando en el piso, acostumbrados a reunirse en dicho lugar cada tarde, cuando se intensifican los bombardeos. La representación de la guerra queda al margen. Zeina Abirached nos muestra sobre todo la aventura de lo cotidiano, pero un cotidiano muy condicionado por los conflictos bélicos que lo rodean. Al adoptar la perspectiva de una menor, el relato de los acontecimientos se ve limitado por la comprensión de la niña, por su visión del mundo.

La obra comienza con un plano general de la ciudad desierta, situada tras unos muros hechos de ladrillos y bidones. El color negro que sirve de fondo y que domina en toda la parte superior de la viñeta sugiere las amenazas que pesan sobre la ciudad. En la parte inferior unas palabras nos sitúan brevemente en el momento y en el lugar de la acción: "Beyrouth Est-1984". Hasta la página 12 las viñetas se suceden sin tramos textuales y la diégesis se apoya principalmente en la capacidad narrativa del dibujo. Las imágenes nos permiten adentrarnos en las calles, vacías, de la ciudad. La presencia de barricadas hechas de ladrillos y bidones se hace cada vez más manifiesta. Los bidones, así como las paredes de las calles, conservan las marcas de los impactos de balas. La mayoría de las ventanas y contraventanas están cerradas y las persianas metálicas de los comercios están bajadas. En los bidones han crecido plantas y hierbajos que dan fe del tiempo que las barricadas han estado ahí. Las viñetas nos presentan un paisaje desolador. Todo está cerrado. Incluso el cartel de ouvert que indica que una tienda podría estar abierta, está situado, irónicamente, sobre un muro de ladrillo. La autora sitúa claramente la acción en un contexto bélico, pero lo hace sin mencionar directamente la guerra y centrándose en la descripción del barrio en el que viven sus personajes.

La importancia del contexto espacial que nos presenta esta serie de planos horizontales se ve reflejada en el tamaño de las viñetas: la primera ocupa una página entera y las siguientes se distribuyen en dos imágenes por página, que nos 
llevan, como una cámara, por las calles de la ciudad. El texto de la página 12 explica por fin las particularidades del paisaje y la presencia inquietante de las barricadas que aparecen en las primeras páginas:

Dans les quartiers situés autour de la ligne de démarcation, des murs de sacs de sable amputent les rues. Des conteneurs, pris sur les quais du port abandonné, sont dressés au milieu des ruelles, pour protéger les habitants des balles des francstireurs [...] À l'intérieur des secteurs cloisonnés, la vie s'organise en fonction des cessez-le-feu (Abirached 2007: 12) ${ }^{1}$

El mundo exterior se presenta como un obstáculo. Los padres tardan más de una hora para atravesar las manzanas que separan la casa de la abuela de su propia casa. Los mapas dibujados por la autora recogen de forma caricaturesca las dificultades que existen en el exterior y que impiden a los padres volver a su casa. Para poder recorrer las calles, los habitantes deben seguir todo un sistema que el texto asemeja irónicamente a una coreografía, en la que, aprovechando los muros y bidones, hay que correr, andar, saltar, trepar, inclinarse o esperar para evitar las balas (MPR 15). Los verbos que más se repiten en la descripción de dicha coreografía son attendre (repetido tres veces) y courir (repetido siete veces). Estos dos verbos evocan perfectamente el estilo de vida de los habitantes de la ciudad. Esperan el fin de los bombardeos, la llegada de los padres, el cambio a un mundo mejor. Sin embargo, deben correr para evitar ser alcanzados por las balas y finalmente optarán por huir hacia otro lugar.

Los mapas dibujados subrayan la restricción del espacio que pueden recorrer los personajes, y que se limita a un cuadrado pequeño de la parte superior derecha de la página 23, señalado mediante el adverbio ici. Dicho adverbio hace referencia no a la totalidad del mapa sino a una parte muy concreta: "Ici, c'est l'espace qui nous reste". En la viñeta siguiente, el espacio se hace más inquietante: el contraste negro-blanco subraya la división de la ciudad. Ici aparece entonces como un lugar al lado de la zona de demarcación. Las calles en el mapa se acaban sobre un vacío, un color blanco que se extiende en la viñeta de las páginas 26 y 27 y que representa la otra zona, todo un territorio que constituye un tema tabú y del cual los niños ignoran la existencia. En esta imagen sólo seis cuadrados, tres a cada lado, representan la zona de los protagonistas. Bajo dichos cuadrados, sin embargo, la presencia de palabras como francs-tireurs, fils barbelés, barils

1. De ahora en adelante, las referencias a esta obra se realizaran mediante las siglas $M P R$ seguidas por el número de página. 
métalliques, conteneurs muestran cómo ese terreno, ya de por sí limitado, está cercado por estos objetos completamente integrados a la geografía cotidiana de la ciudad. La viñeta de la página 28 hace un zoom sobre los bidones que constituyen a la vez una protección y una reja que limita la libertad de movimiento de los personajes. Como subraya Daniele Barbieri, contrariamente a la imagen del cine, "el encuadre del cómic puede jugar también con la variabilidad del formato de las imágenes" (1998: 138-139). El tamaño de cada viñeta y su relación gráfica con las otras imágenes teje una red de significaciones que es esencial en la novela gráfica de Zeina Abirached.

Del portal del edificio las viñetas nos van conduciendo, como una cámara, a la puerta de la casa de los protagonistas y finalmente al interior del piso. Como señala Ricœur (2000: 49), las cosas que recordamos están intrínsecamente asociadas a lugares. Los lugares en los que hemos vivido son memorables. La memoria declarativa los evoca y los cuenta, puesto que los recuerdos están asociados a ese espacio (Ricœur 2000: 51). Esto explica que el espacio, tanto exterior como interior, adquiera tanta importancia en la obra de Abirached.

Los mapas dibujados por la autora ilustran la manifestación de la guerra en el espacio. Muestran las zonas de demarcación entre los barrios controlados por las distintas milicias y el lugar en el que se sitúa el apartamento de la protagonista. Esto permite al lector observar hasta qué punto el piso de la familia está cerca del conflicto. Los mapas indican cómo el espacio en el que viven los personajes ha ido haciéndose más pequeño por miedo a las bombas, hasta limitarse a la entrada del piso, el único lugar que consideran seguro al estar más alejado de la línea de tiro (MPR 34). La entrada acoge tanto a los habitantes del apartamento como a los vecinos, que bajan a dicho lugar para protegerse de los bombardeos: "Comme nous habitions au premier, l'étage le moins exposé aux obus, l'entrée de notre appartement était la pièce la plus sûre de tout l'immeuble...Et les voisins avaient pris l'habitude de s'y retrouver les soirs de bombardement" (MPR 41).

La viñeta de la página 35 pone de relieve las dimensiones reducidas de este espacio al presentarlo dentro de un cuadrado pequeño en el centro de la página y rodeado por un fondo blanco, que pone en evidencia el aislamiento de los personajes que viven en él. Zeina Abirached insiste sobre la importancia de la falta de color en esta obra:

[...] ce noir et blanc raconte une histoire par lui-même, avec ce que ça induit de vide et de plein dans l'image. Il $\mathrm{y} a$, par exemple, une scène où je ne dessine quasiment rien. Il y a juste un fond noir avec des dialogues et le noir permet au 
lecteur d'imaginer la scène, parce que c'est quelque chose d'assez insupportable, d'indicible ou d' « indessinable ». De la même façon, le blanc m'a permis aussi d'exprimer le vide de cette ligne de démarcation entre les deux moitiés de la ville. Évidemment, c'était violent, c'était détruit. On peut imaginer des scènes de guerre atroces, mais il n'était pas question de les dessiner. En revanche, le blanc venait dire : «Remplissez le vide vous-mêmes ! (Abirached y Bouillon 2015: 141)

Como señala Hirsch (2011: 21), el horror no reside necesariamente en las imágenes, sino en la historia que el lector o el espectador reconstruye al rellenar los huecos entre las imágenes mostradas.

El aislamiento de los personajes se ve incrementado por la falta de infraestructuras que faciliten la comunicación entre las distintas casas. La cantidad de viñetas que la obra dedica al teléfono pone de relieve la importancia que adquiere esta forma de comunicación ante el miedo de salir a la calle. En total encontramos unas 36 viñetas en las que el teléfono es un elemento esencial de la acción, y entre las que se encuentran dos primeros planos de dicho aparato y doce planos detalle. Como señala Pierre Fresnault-Deruelle, el sentido general nacido de una sucesión, es el que determina a cada instante el valor de una imagen (1972: 49). De la página 18 a la página 20, unas veinticinco viñetas se centran en describir la lentitud con la que funciona la comunicación telefónica. Estas viñetas, que sugieren el paso del tiempo, subrayan la experiencia subjetiva de ese momento que están viviendo los protagonistas. La espera se convierte en un motivo esencial en estas escenas en las que el paso del tiempo se ve reflejado por el humo de los cigarrillos de los adultos, que aumenta, así como por la actitud de los niños que, impacientes, acaban por ponerse a cantar y a jugar. Entre las escenas en las que la madre marca el número de teléfono y aquellas que muestran la conversación que tiene lugar, la narración inserta toda una serie de viñetas que se centran en la descripción del espacio. Esta técnica narrativa permite subrayar la lentitud con la que se realiza la comunicación telefónica.

La diégesis también resalta la carencia de luz eléctrica, agua y alimentos que caracteriza esa sociedad. La narración subraya las dificultades que encuentran los protagonistas para conseguir alimentos básicos o gasolina: "On faisait la queue devant les magasins pour trouver du pain, du riz, du sucre, des conserves, des cigarettes, du café, des allumettes, des bougies, des bonbonnes de gaz pour les camping-gaz, des piles pour les lampes de poche et les radios" (MPR 68). Tampoco hay agua corriente: los protagonistas intentan racionar las reservas de agua que consiguen sacar de un pozo y que dividen en "eau pour boire" y "eau pour se laver" (MPR 92). Después de bañarse los niños, y haciendo referencia al cuarto 
de baño desordenado que han dejado, el texto señala: "Il y a une expression au Liban pour désigner un endroit très désordonné. On dit qu'il est comme « une salle de bain dont on aurait coupé l'eau ! »" (MPR 98). La relación entre el dicho y la realidad dramática de los personajes es evidente.

\section{La vida cotidiana: entre solidaridad y violencia}

La historia se centra en un día en el que los bombardeos impiden que los padres, que han ido a visitar a la abuela, regresen a su casa. Si la narración escoge este día en concreto, puesto de relieve por "ce jour là" (MPR 13), la historia hace hincapié en la dimensión cotidiana de la realidad que nos presenta, en el día a día de la vida de los personajes, así como en el contraste entre el presente y el pasado de éstos.

La abuela recuerda con nostalgia los viajes que hacía antaño con su marido y que enumera: "Hasroun, Les Cèdres, Laklouk, Bologna, Aley, Souk-El-Gharb, Nahb-El-Safa, Kfarnis, La Békaa, Jezzine, Bkessine...Et j'en passe !” (MPR 16). Ahora no puede más que quedarse sentada junto al camping gas que antaño utilizaba en sus acampadas, y que ahora calienta y alumbra su casa a pesar de no funcionar correctamente. Las viñetas nos introducen en el interior oscuro de la casa de este personaje, donde los padres de la narradora permanecen aislados.

Paralelamente, los vecinos van bajando al piso en el que los niños aguardan la llegada de sus padres. Cada vecino tiene una historia. El padre de Chucri, Saïd, un taxista, desapareció una noche cuando volvía a casa. Desde entonces, y para ganarse la vida, Chucri se encarga de ayudar a la gente, reparando los destrozos hechos por las balas, yendo a por agua y gasolina, o encargándose de los problemas de electricidad mediante un pequeño generador eléctrico que él mismo ha instalado. Ernest, el vecino del tercer piso, era profesor de francés antes de la guerra. Su hermano gemelo, Victor, murió, abatido por un franco-tirador, y desde entonces Ernest no sale del edificio. Mediante una analepsis, la narración nos muestra momentos en los que los hermanos jugaban juntos al tric-trac en la calle (MPR 78). En el presente, Ernest sigue jugando, ya no en la acera, sino en su casa, y ante una silla vacía a la que le habla como si su hermano siguiera con vida. En cuanto a Monsieur Khaled, el vecino del cuarto piso, tenía un restaurante que fue destruido por los bombardeos. Su mujer, Mme Linda fue Miss Líbano en los años sesenta. Ambos tuvieron que mudarse a este edificio porque su antiguo piso era un blanco fácil para los aviones. Khaled recuerda con nostalgia su barrio natal, que compara con la ciudad de Texas, puesto que: "le Texas...c'était ce que 
Khaled avait trouvé de plus éloigné pour désigner le quartier de Beyrouth-Ouest où il avait vécu et dont la guerre l'avait privé" (MPR 108). Finalmente, Farah y Ramzi viven en el segundo piso del edificio. Los padres de Farah se fueron a París, huyendo de la guerra y Anhala, la criada, se quedó con Farah y su marido. Ramzi estudió arquitectura pero no tuvo tiempo de ejercer su profesión a causa de la guerra. Cuando la casa de los padres se incendió tras ser bombardeada, su marido y ella se instalaron en este edificio. Cada personaje tiene una historia, que representa también la historia de Beirut. Las viñetas oponen la vida actual de los personajes y su pasado para mostrar las consecuencias dramáticas que el conflicto ha tenido a nivel social e individual. La narración sigue una dinámica de vaivenes: las viñetas nos llevan del exterior al interior de las casas, del presente al pasado, los personajes llegan o se van.

Según Régine Waintrater, ningún relato puede contar todo el horror. Éste no puede narrarse de forma linear: es difícil construir y escuchar el relato testimonial marcado por el trauma (2004: 86). En Mourir, partir, revenir: Le jeu des hirondelles, la violencia exterior aparece reflejada sobre todo mediante las noticias que permite escuchar la radio. La repetición de las escenas en las que aparece dicho aparato destaca la importancia de éste. A través de la radio los personajes pueden escuchar la larga enumeración de lugares que han sido bombardeados. En un primer momento esta enumeración se realiza mediante una serie de viñetas de tamaño mediano ( $M P R$ 82). Sin embargo, ésta se hace más presente todavía en una viñeta que ocupa la totalidad de la página y que recoge de arriba abajo toda una serie de bocadillos que enumeran los actos de violencia que han tenido lugar: "Affrontements sur l'axe Primo-Sodeco", "Pionnage de la zone Berjaoui-Stade du Chayla", "Chute d'Obus sur le périmètre de la Villa Mansour". Las últimas noticias señalan la dimensión de la catástrofe: "81 morts et 221 blessés", "mobilisation des organisations humanitaires" (MPR 85). La posición de los personajes sentados y con mirada apesadumbrada bajo toda esa lluvia de noticias es muy reveladora.

La narración interrumpe las escenas que presentan las noticias transmitidas por la radio. La inserción de una analepsis que muestra el momento de la desaparición de Saïd, el padre de Chucri, pone en paralelo la violencia de 1984 y la violencia de 1976. Los soldados que hacen bajar a Saïd del coche y que le hacen desaparecer son jóvenes, aunque la historia sólo nos permite escuchar sus voces. Un simple "clic" sobre un fondo negro nos indica a la vez que se ha apagado el motor del coche y que el personaje ha desaparecido. El texto señala: "Les personnes contrôlées pouvaient se faire arrêter, enlever ou assassiner sur la simple base de leur religion, inscrite alors sur la carte d'identité" (MPR 84). 
La guerra no aparece directamente, al igual que el enemigo no se ve en ningún momento. Los rostros de los soldados que hacen bajar a Saïd del coche no aparecen en las viñetas, y se limitan a ser unas voces que surgen del fondo oscuro de la imagen. En la obra, las cosas que cuenta la narración son tan importantes como las que no dice, las que calla. Mediante toda una serie de inserciones, analepsis y repeticiones la narración pone de relieve las características de la sociedad en la que viven los personajes. La violencia es omnipresente y sin embargo la diégesis consigue relegarla al margen, al igual que los personajes intentan vivir bajo una aparente normalidad a pesar de la amenaza latente.

A pesar del conflicto externo que se está produciendo, Abirached centra la historia en la vida rutinaria de los personajes, en su día a día. Greice Schneider ha mostrado la importancia que ha adquirido la temática de la vida diaria e incluso del aburrimiento en el género del cómic (Schneider 2016). Los protagonistas de Abirached hacen pasteles (utilizando solamente los ingredientes de los que disponen, es decir harina, aceite, azúcar y cúrcuma), conversan, cantan, leen, actúan y juegan. Ernest sigue vistiéndose de forma elegante y a pesar de las restricciones de agua sigue regando las plantas cada miércoles, como una forma de conmemorar a su hermano, muerto un miércoles por la tarde. Las plantas constituyen un motivo importante de la obra. Los hierbajos que han crecido en los bidones subrayan el paso del tiempo, pero también la posibilidad de la vida, de un renacimiento, que todavía se ve amenazado por la presencia de la guerra que se encarna en los muros de ladrillos.

El aspecto rutinario de la vida de Ernest queda reflejado perfectamente en las viñetas de las páginas 71 a 74 en las que se nos muestra cómo los niños son capaces de predecir exactamente el momento en el que llegará este personaje al piso. Ernest se viste, se acicala, escoge un libro, se pone el abrigo y el sombrero y baja las escaleras iluminando el camino con una linterna. El texto subraya el carácter cotidiano de los actos del personaje: "Tous les soirs, 10 secondes exactement après le vroooaaaam de démarrage du moteur, Ernest Challita tapait avec sa clé sur la vitre de notre porte" (MPR 74).

Los protagonistas comen, duermen, beben. Las viñetas están repletas de onomatopeyas que presentan también ruidos cotidianos como el "SHLLRRP" de tomar café, el "RZZ" de los ronquidos del personaje que duerme, o el "grouïk" del estómago hambriento.

El conflicto bélico tampoco impide que se celebren días especiales, como el de la boda de Farah, que los personajes rememoran mediante las fotos que con- 
siguieron salvar del incendio del piso en el que vivían anteriormente. Las viñetas describen los distintos preparativos que se hicieron para la boda: el vestido, los zapatos, el peinado, el maquillaje, la manicura. Sin embargo, para llegar a la iglesia, situada enfrente, los invitados tuvieron que correr para evitar las balas: "pour éviter le franc-tireur, on a dû courir de chez mes parents jusqu'à l'église, et puis de l'église jusqu'à chez mes parents" (MPR 132). La fiesta que se realizó en un piso tras la ceremonia, y que aparece destacada en varias viñetas, contrasta considerablemente con la realidad exterior. Este aspecto aparece realzado en la imagen que ocupa las páginas 134 y 135. La viñeta nos muestra la fiesta que se está celebrando en un piso y la alegría de los invitados, pero encima de la ciudad y sobre un fondo negro que domina la escena, aparece el ruido ensordecedor de las bombas destacado por la onomatopeya: "BRRAAAAAM". Las imágenes cotidianas de dentro del apartamento se yuxtaponen a las de la guerra que invade las calles de alrededor. Esta yuxtaposición es característica de la obra de Abirached que muestra a la vez un entorno exterior hostil y un espacio familiar íntimo y protector.

La historia alterna constantemente momentos de miedo o consternación y momentos de alegría y fraternidad. Anhala recuerda el viaje a París que hizo con la familia de Farah cuando ésta era pequeña. De París afirma: "C'est tellement grand que les gens que tu croises dans la rue, eh bien tu es sûr de ne plus jamais les revoir" (MPR 57). Al anonimato y al tipo de relaciones sociales que caracterizan la vida en otros países, el texto opone la humanidad y la cercanía que existe entre los protagonistas. La obra hace hincapié en la generosidad de los personajes. Chucri trae una lechuga lavada, para comerla entre todos. Anhala hace café y ofrece a sus vecinos pastel recién hecho. Monsieur Khalet siempre trae alguna botella de alcohol que conserva todavía de su antiguo restaurante, para compartirla con sus vecinos. Ernest actúa delante de los niños cada noche, citando párrafos enteros de Cyrano de Bergerac. Chucri juega frecuentemente con ellos.

A pesar de intentar distraerse, los personajes están consternados por la violencia y el peligro que corren. Su inquietud aparece subrayada mediante toda una serie de viñetas que prácticamente se repiten y en la que los personajes, callados, se miran, suspiran o exclaman "pauvres de nous", "pauvre pays" (MPR 86). Ernest compara la tranquilidad con un pequeño recreo: "profitons de cette petite, euh... récréation", dice Ernest, "avant qu'ils ne se remettent à tout casser..." (MPR 101).

La viñeta de la página 39 nos muestra la familia, compuesta por la madre, el padre, el hijo y la hija. En la imagen, los niños aparecen sonrientes, mientras 
que los padres se miran, preocupados. Las palabras de la narración en primera persona muestran la ingenuidad de los niños, que no comprenden la magnitud del peligro que corren: "Réunis ainsi dans l'entrée, rien ne pouvait nous arriver" (MPR 39). Estas palabras representan su ingenuidad pero también la necesidad de esperar estar a salvo. De hecho, incluso los adultos utilizan expresiones similares para tranquilizarse mutuamente. La abuela, en mitad de la oscuridad, afirma: "Je pense qu'on est quand même, peut-être, plus ou moins, en sécurité ici" (MPR 21). Chucri, para calmar a los demás personajes señala: "Ne t'en fais pas", "Tant qu'on est dans l'entrée rien ne peut nous arriver !" (MPR 87); "Ne vous inquiétez pas !", "Je vous assure qu'on est encore en sécurité ici" (MPR 90). Los personajes intentan animarse los unos a los otros: "ne t'inquiète pas", "ne te décourage pas", "oui, tout va bien se passer" (MPR 117). Sin embargo, todas estas frases pronunciadas contrastan con la seriedad y la mirada apesadumbrada de los personajes en las distintas viñetas. Los protagonistas escuchan cómo los misiles salen y llegan a su destino. Las bombas se convierten en simples ruidos que los personajes separan en "départ" y "arrivée" (MPR 110-111). La lámpara del cuarto de Anhala, que se mueve a cada disparo, recuerda la violencia que existe en el exterior. Incluso desde la cama, Ramzi oye las instrucciones que les dan a los artilleros: "au-dessus ?", "en dessous?" (MPR 118 y 120). Las repeticiones que aparecen en estas escenas subrayan la amenaza constante que rodea a los personajes y recupera o se hace eco en cierto modo de las tiras en las que Chucri y Ernest distinguen la salida y la llegada de los misiles.

Tras la llamada de la abuela a Anhala, el suspense de la historia se intensifica puesto que los padres que han salido hace una hora de casa de la abuela todavía no han conseguido llegar. Las viñetas que muestran la consternación de los personajes se incrementan cuando, a pesar del peligro, Chucri sale a buscar a Sami y Nour. La presencia creciente de los "Tic-Tac" en las viñetas subraya la dura espera de los personajes y aumenta el suspense de la acción (MPR 148-151).

Cuando los padres regresan, la aparente normalidad vuelve a instalarse. Los personajes beben café, Ernest lee Cyrano de Bergerac a los niños. Sin embargo, esta normalidad se detiene bruscamente en el momento en el que una bomba alcanza el piso: "Et tout à coup, je n'ai plus rien entendu" (MPR 163), "L'obus était tombé dans ma chambre" (MPR 165). Las sillas vacías, el humo y los edificios en ruinas que aparecen en las viñetas siguientes destacan la magnitud de la catástrofe. 


\section{Conclusión: un futuro incierto y una tradición rota}

A lo largo de la obra algunos personajes conservan la esperanza en un futuro próximo mejor: "dans un an maximum, c'est fini, on n'en parle plus, et on recommence à vivre comme avant", afirma Chucri, y añade: "L'essentiel, d'ici là, c'est de continuer à vivre" (MPR 52). Los personajes se plantean si deberían quedarse en el país o si deberían huir a otro lugar para escapar de la violencia y los bombardeos. Muchos ya han decidido marcharse. La madre de Chucri decidió irse de Beirut y vivir en un pueblo en el norte del Líbano. Los padres de Farah se fueron a París. Ramzi quiere reunirse con su hermano, que ha abierto un estudio de arquitectura en Montreal. Farah siempre lleva encima sus pasaportes y dinero en efectivo, por si necesitan huir de repente. La dialéctica que se impone es la de quedarse y salvar el país o irse y salvarse uno mismo. La mayoría opta por la segunda opción. Como afirma Chucri, "si j'avais un enfant, peut-être que j'aurais tout fait pour partir moi aussi” (MPR 65).

La obra destaca también la importancia de la filiación y de las raíces de los personajes, que se ven en cierta forma rotas por el drama y la emigración. La finca donde viven los protagonistas representa las raíces de la familia de la narradora: "mes grands-parents paternels y ont habité toute leur vie" (MPR 30), “ $\mathrm{j}$ 'ai grandi dans l'appartement du premier étage, où mon père est né" (MPR 31). Se trata, sin embargo de unas raíces que deberán abandonar simbólicamente al final de la historia, cuando una bomba alcance el edificio.

A lo largo de la obra, la entrada en la que viven los personajes está caracterizada por la presencia de un tapiz, que aparece en muchas de las viñetas, y que ilustra la huida de Egipto de Moisés y de los hebreos, una huida que anuncia la de la mayoría de los protagonistas. Los padres se mudan con los niños a otra casa, pero vuelven, sin embargo, a recoger el tapiz, lo único que les queda del abuelo paterno y del piso destruido. La página en blanco que aparece en las páginas 73 y 74 representa el paso del tiempo (una semana desde que se van hasta que los padres vuelven a recoger el tapiz al edificio), pero también simboliza el vacío que se queda tras la partida.

Anhala lleva en la familia de Farah sesenta y cinco años. Llegó a casa de los bisabuelos de Farah a los diez años como criada y presenció el nacimiento de la abuela y de la madre de Farah, así como el de la niña, que en el momento de la historia es ya adulta y está embarazada. Anhala representa la memoria del pasado mientras que el hijo de Farah que está a punto de nacer representa el futuro. Anhala se niega a marcharse a otro país: "Non, ils s'en iront sans moi... 
Aujourd'hui je suis trop vieille pour changer quoi que se soit" (MPR 64). Farah, en cambio, quiere que su bebé nazca en Montreal y no en el lugar en el que se han visto obligados a vivir, un despacho lleno de maletas. Las diferencias que dicho cambio cultural supondría se ven reflejadas en la elección del nombre del bebé. La madre preferiría ponerle un nombre como "Kamil", cuyas sonoridades similares a las del nombre francés "Camille" facilitarían la integración social de su hijo en Canadá. Sin embargo, eso significaría romper con la tradición familiar: "dans la famille de Ramzi, les fils aînés s'appellent Abdallah et Walid de père en fils depuis au moins six générations !" (MPR 125). La importancia de la onomástica aparece de nuevo en las penúltimas páginas de la obra, en las que la narradora escribe su nombre en árabe y afirma: “j”ai appris à écrire mon nom" (MPR 182).

Más que en la guerra en sí, la obra insiste particularmente en la solidaridad y generosidad de los habitantes y en las dificultades de conciliar el pasado o la tradición y el futuro. Cuando los padres de la narradora vuelven al piso a por el tapiz, el edificio está vacío, sólo se han quedado Ernest y Chucri. Khaled y Linda se han ido a vivir a Jounieh, Farah y Ramzi se han ido a Montreal, donde nacerá el bebé y Anhala se ha ido a vivir con la tía de Farah. En las viñetas de la página 169 a 172, un coche destaca el viaje que los personajes emprenden hacia otro lugar. La combinación de fotografía y dibujo confiere más realismo a estas escenas, y principalmente al grafiti pintado en un muro próximo a la línea divisoria, que para la autora simboliza el sentimiento de los libaneses. Las palabras del grafiti señalan: “mourir, partir, revenir c'est le jeu des hirondelles". Esta frase se hace eco del vaivén incesante de los libaneses, de su necesidad de huir para no sucumbir a las bombas, de abandonar el lugar donde han nacido para buscar un futuro mejor, pero también de la necesidad de volver para no abandonar del todo sus raíces: volver como los padres de la narradora a por el tapiz o volver como la propia autora ha hecho al plasmar su propia infancia en esta obra.

Según Gálvez, la novela gráfica se caracteriza sobre todo por su "ambición expresiva, en la voluntad de abarcar objetivos narrativos más profundos" (2008: 71). En Mourir, partir, revenir: Le jeu des hirondelles, Zeina Abirached utiliza numerosos recursos gráficos y narratológicos con el fin de plasmar la vida cotidiana durante la guerra civil libanesa. La obra nos introduce en la vida privada de una niña cuyos momentos de felicidad se ven truncados por el peligro que supone la guerra. Las imágenes, más que las palabras, presentan la angustia de la protagonista y reflejan los límites de la comprensión de ésta 
de lo que está pasando a su alrededor. A través de la mirada de la niña, ese mundo cotidiano marcado por la guerra nos es descrito bajo una capa de normalidad, sin dramatismo. Sin embargo, la obra sí que refleja cómo esos momentos rutinarios se ven marcados por momentos de angustia, como el de la larga espera a que vuelvan los padres. La obra no muestra imágenes sangrientas de la guerra sino que introduce páginas en blanco o negro. Estas lagunas dejan entrever los recuerdos traumáticos de la autora, al mismo tiempo que invitan al lector a imaginar el horror del conflicto bélico, un horror que se hace más cruel si cabe al aparecer yuxtapuesto a la vida rutinaria e inocente de los niños y de toda esa comunidad solidaria.

\section{Bibliografía}

ABIRACHED, Z. (2007). Mourir, partir, revenir: le jeu des hirondelles. París: Éditions Cambourakis.

ABIRACHED, Z. (2008). Je me souviens. París: Éditions Cambourakis.

ABIRACHED, Z. y BOUILLON, H. (2015). "Un jeu de ping-pong entre la France et le Liban". Hommes et migrations 1311 (3): 140-143.

BAETENS, J. (2013). "Uncaging and Reframing Martin Vaughn-James's The Cage" en Drawing from life. Memory and subjectivity in comic art. (Coord. J. Tolmie). Mississippi: University Press of Mississippi: 67-85.

BARBIERI, D. (1998). Los lenguajes del cómic. Barcelona: Paidós.

BARTHES, R. (1980). La chambre claire: Note sur la photographie. París: Gallimard.

BENNETT, J. (2005). Empathic vision: affect, trauma, and contemporary art. Stanford: Stanford University Press.

CARUTH, C. (1995). Trauma: explorations in memory. Londres: Johns Hopkins University Press.

CALARGÉ, C. y GUEYDAN-TUREK, A. (2014). "La guerre du Liban à/et l'écran des souvenirs dans Le jeu des hirondelles et Je me souviens. Beyrouth de Zeina Abirached". French Cultural Studies 25 (2): 202-220.

CHANEY, M. A. (Coord.) (2011). Graphic subjects: critical essays on autobiography and graphic novels. Wisconsin: University of Wisconsin Press.

CHUTE, H. L. (2010). Graphic women: life narrative and contemporary comics. Nueva York: Columbia University Press.

CHUTE, H. L. (2016). Disaster drawn. Visual witness, comics and documentary form. Cambridge: Harvard University Press. 
CORTÉS, N. et al. (2008). De los superhéroes al manga: el lenguaje en los cómics. Barcelona: Centre D’Estudis i Recerques Social i Metropolitanes y Universitat de Barcelona.

DABITCH, C. (2009). "Reportage et bande dessinée". Hermès 54: 91-98.

EL REFAIE, E. (2012). Autobiographical comics. Life writing in pictures. Mississipi: University Press of Mississippi.

FELMAN, S. y LAUB, D. (1992). Testimony. Crises of witnessing in literature, psychoanalysis, and history. Nueva York: Routledge.

FRANCIS, J. Y. (2017). Trauma expressed through space, frames, and color in franco-arab graphic novels. Trabajo de Fin de Máster defendido en la Universidad de Carolina del Norte, Chapel Hill.

FRESNAULT-DERUELLE, P. (1972). La bande dessinée: l'univers et les techniques de quelques 'comics' d'expression française. París: Hachette.

GÁLVEZ, P. (2008). "La novela gráfica o la madurez del medio" en De los superhéroes al manga: el lenguaje en los cómics. (Coord. N. Cortés et al.). Barcelona: Centre D' Estudis i Recerques Social i Metropolitanes y Universitat de Barcelona: 69-110.

GARCÍA, S. (2010). La novela gráfica. Bilbao: Astiberri.

HIRSCH, M. (2001). "Surviving images: Holocaust photographs and the work of postmemory" en Visual Culture and the Holocaust. (Coord. B. Zelizer). New Jersey: Rutgers: 215-246.

HIRSCH, M. (2011). "Mourning and Posmemory", en Graphic subjects: critical essays on autobiography and graphic novels. (Coord. M. A. Chaney). Wisconsin: University of Wisconsin Press: 17-44.

MONTENEGRO, C. (2011). "Novelas gráficas: una reconstrucción de la memoria". Ignire: 19-30 <http://www.ignire.cl/index.php/articulos2/107-63>. (Acceso 20 septiembre 2017).

RICCEUR, P. (2000). La mémoire, l'histoire, l'oubli. París: Éditions du Seuil.

ROCKFORD, S. (2015). L'identité libanaise dans la mémoire littéraire de la guerre civile. Trabajo de Fin de Máster defendido en la facultad de Colby College $<$ http://digitalcommons.colby.edu/honorstheses/798/>. (Acceso 27 septiembre 2017).

SCHNEIDER, G. (2016). What happens when nothing happens. Bordedom and everyday life in contemporary comics. Lovaina: Leuven University Press.

TOLMIE, J. (Coord.) (2013). Drawing from life. Memory and subjectivity in comic art. Mississippi: University Press of Mississippi.

VERREAULT-CÔTÉ, C. (2012). 'Je' s'engage? La relation entre littérature de conscientisation et autobiofiction dans les romans graphiques de Guy 
Delisle. Trabajo de Fin de Máster defendido en la Universidad de Concordia $<$ https://spectrum.library.concordia.ca/975055/>. (Acceso 29 septiembre 2017).

WAINTRATER, R. (2004). "Le pacte testimonial" en Témoignage et trauma. Implications psychanalytiques. (Coord. J.-F. Chiantaretto). París: Dunod: 65-97.

ZELIZER, B. (1998). Remembering to forget: Holocaust memory through the camera's eye. Chicago: University of Chicago Press. 